know exactly what it was-a thick embedded cyst of the broad ligament. As Dr. Keith was wrong in his diagnosis and is wrong in his recollections, we can place n's reliance whatever on his conclusions.

My own conclusion about this case is that the death was really due to delay in performing. Dr. Keith ought to have performed it two years before it was done. He knew at that time how to deal with these troublesome broad ligaments, and for years he had promised to comply with my constantly-repeated request to see him do a hysterectomy. But he as persistently broke his promise, and finally, when pressed into a corner on the subject, refused to fulfil it. Had I been in possession of what Dr. Keith kept secret, I could have operated upon this poor woman successfully, and upon many others. Had Dr. Keith done the operation himself it would probably have been successful. The death should therefore be recorded against Dr. Keith and it is very hard that I have to bear the odium of the failure.

That the case was one of uterine myoma never entered my mind; but I knew it was a bad case before the operation, because the whole thing was so fixed; and I began then to suspect what I now know to be the fact, that Dr. Keith habitually made a selection of cases for operation. Of course such a practice will yield results that cannot be compared in any fairness with the results of men who, despising such methods, operate upon all cases which demand it without reference to selection for results.

Dr. Keith says: "From the fact that in my cases of hysterectomy the removal of the uterus and ovaries was sooner or later followed by insanity in 10 per cent. of the whole number is enough for me to condemn any operation that removes these organs." This is a prodigious statement, quite out of harmony with my own experience. In not one of my hysterectomies has insanity followed the operation.

I have seen insanity follow removal of the appendages for myoma in two cases, but in one the patient was insane from the moment she came out of the chloroform, and she was "queer" before she went under it. I have seen insanity follow simple unilateral ovariotomy, and also simple exploratory incisions. It is well known to occur after all surgical operations and even after the administration of anæsthetics; but we know nothing yet to make us believe that the projortion of cases of insanity amongst persons who have been thus operated upon is higher than it is amongst the general population who have never had any surgical treatment. And, even if it were higher, the question is after all a relative one: do 97 women out of 100 recovering from an operation which will cure 92 or 93 of them suffer more because a few of them will go insane than if the whole 100 are left to suffer and bleed and die? It is not, as Dr. Keith rightly says, a question of surgery, but a question of humanity; and, if he can cure his cases by electricity, so much the better for humanity. But he gives no proof, and he gives no details of his marvellous methods, methods which must be vastly different from and very superior to those of Apostoli; and until he does so the assertions about electricity are no more than words.

\section{CLINICAL NOTES LEPROSY.}

BY JAMES J. L. DONNET, M.D.,

Inspector-General of Hospitals and Fleets; Honorary Surgeon to the Queen

THE following summary of cases of leprosy-anæsthetic and tuberculous-may prove interesting at this time, when the public mind-earnest in its anxiety-is using its every endeavour towards alleviating, if not stamping out, this loathsome disease.

These cases were observed in Lisbon at the IIospital of San Lazaro in the years 1866-67, during my administration as medical officer in charge of Her Majesty's Royal Naval Hospital established in that city.

This Lazar hospital is dependent upon the large hospital of San Jose, and is set aside for the reception, treatment, and segregation of leprosy. The two types which are seen in this hospital are those of lepra anæestheticu and lepra tuberculosa. The first is known to the Portuguese by the name of gafeira, the last by that of morphœa.

The cases are as follows:-

CASE I. September, 1866. Lepra Ancesthetica.-M. J. G., aged 38. Born in the province of Minho in 1828. Has lived for the last twenty years on the seaboard of Lisbon as a vintner. His diet has been of a varied nature, using flesh meat frequently. Both parents are living. Neither they nor any of his brothers or sisters are affected with leprosy. Remarked a scaly eruption of his skin shortly after his arrival in Lisbon. In the year 1857 he experienced for the first time a difficulty in the use of his hands ; the left little finger became stiff, and stiffness of the other fingers of the left hand followed. The right hand shortly after became affected in the same way. The muscles of both hands, especially of thumbs, have shrunk in size, the fingers are flexed, and cannot be extended under the use of a moderate force; the integuments are thickened at the joints of the fingers; the fingers are dwindled in size, and their distal extremities are being absorbed; the nails have somewhat shrunk, are adunque, and of a dark hue. The sensibility of both hands, of wrists, and of part of forearm is lost; the elbow is still sensible when touched. Ankle jcints are stiff; the integuments of the arch of the feet are thickened. Hair of head plentiful, that of eyebrows and eyelids fast disappearing; the lower eyelids are drawn downwards, and are with difficulty closed; they seem glued to bone. Fauces red; respiration and deglutition easy. Was never vaccinated; has had small-pox twice-when an infant and again at the age of 5 . Never had syphilis, but has suffered from gonorrhœa. Has been six years in San Lazaro.

CASE II. September, 1866. Lepra Tuberculosa.-F. T., aged 32, native of Estremadura. Has been living in Belem, near Lisbon, for the last six years, five years and a half of which he has been in San Lazaro. Was educated for the Church, delivering lectures at different colleges whilst thus preparing. Father and mother living, both in good health. Family consisted of eight; the two youngest are the only ones affected with leprosy, he being the elder of the two. Has the disease in the tubercular form, whilst his younger brother has it in the anæsthetic. None of the collateral branches of the family are in any way affected. Is temperate and regular in his habits; never had any more serious illness than measles when young. It was in the year 1856, being then 22 years of age, that he fell subject to a severe cold, which affected and obstructed his nasal respiration, and deadened in some measure his olfactory sense. About this time there appeared a small tubercle on the free edge of the upper eyelid, for which he consulted a surgeon, who excised it. It, however, returned, and others of a similar tubercular nature followed on legs, eyebrows, and hands. These swellings made their appearance all about the same time, gradually enlarging until they attained the size now observed. The sensibility of the skin is only diminished on the tubercle and where the skin is thickened; the tubercles being insensible to the prick of a pin. The sense of touch is not affected, for with his hands he can accurately ascertain the form, the degree of heat, of hardness and softness of any and every article he examines. The hands and fingers have the appearance of being affected with chilblains; when allowed to hang they give to the patient a sense of leaden heaviness. They are sensitive to both heat and cold. Eyesight entirely gone; there is a deposit of plastic lymph between the layers of the cornea; sense of smell is sometimes entirely absent, but when a free discharge takes place from the nasal cavity sense of smell becomes perfect, and respiration is rendered easier. The patient explains this by saying that tubercles form within the nasal cavity, grow, break, and scab over, the sense of smell is then lost by the pressure made by the scabs on the extreme filaments of the olfactory nerve; but when the scabs are thrown off and a free discharge follows, the nerves, being free, reacquire their power. The salivary glands are swollen, the saliva is secreted abundantly during the day, whilst at night, from the respiration being effected exclusively by mouth, it is dried up, giving a sense of parchness and dryness very distressing. Tongue large and chapped. Pulse slow, 65 per minute. Where the skin is thickened it is of a dusky hue. Hair of head thin; none on eyebrows or eyelids; it is fast disappearing from face and shins, but is natural in both axillæ and pubes. $\mathrm{He}$ is puzzled how to account for the causes which originated the disease in him; if not to the cold he contracted at the age of 22 , he 
knows of no other reason; for, with the exception of the Fridays and Saturdays and fast days throughout the year, he has used flesh meat as his ordinary diet, has lived generously, temperately, and used life, never abusing it.

CASE III. 1866. Lepra Tuberculosa.-D. F., aged 22, born in Certao Beira Baixo. Has been seven years in Lisbon, six years in San Lazaro; father and mother are living and healthy ; employed as an agricultural labourer; of eight children (four boys and four girls), four have become victims of leprnsy; two alone are now living; he is one of the affected now surriving; a female cousin of his father's, who died at the age of 60 , bezame affected with the disease in the latter years of her life. At the age of 15 he came to Lisbon to learn the trade of a shoemaker, but, becoming soon after affected, he was unable to follow it out. He tended sheep up to that age, and lived chiefly upon bacalhao, sardines, or salted tunny fish. It was only after coming to Lisbon that he was able to indulge in flesh meat. Never was affected with any disease except scabies, which sulphur soon cured. He had only been a year in Lisbon when his attention was drawn to a tubercular growth which made its appearance on the ankle of the left foot, which would have had but little significance had not others soon followed on different parts of his body. The skin of forehead and face now thickened, and a year after the integuments of hands enlarged. The face is interspersed with knobs of a dusky hue, the cheeks are swollen, the furrows from alæ nasi to corners of mouth are deepened, the nose flattened, the nostrils broad, upnn their edges are several tubercles, some ulcerated and discharging, others scabbed over and dry; lips thick, projecting; the lower lip hangs; ears thickened, the lobes more especially, the conchæ are contracted. Sight of one eye endangered by a deposit on cornea ; the upper eyelid of this eye is thickened and hangs, giving the appearance of one affected with ptosis. Hands thickened as if by chilblains. No sense of itching of tubercles. Respiration difficult and labouring, as if endeavouring to overcome some obstruction in the air-passages. Mouth dry at night. Salivary glands not affected.

CASE IV. Lepra Anasthetica.-M. M. R., aged 68, native of Cinco Villas, near Coimbra, a shoemaker by trade; has been fifty-four years in Lisbon, sixteen of which have been passed in San Lazaro. When 21 sears of age he was affected with a scaly form of disease, which, however, gradually disappeared, leaving no sign of its existence behind. It was when the skin became free that he experienced a sense of numbness of the left hand, followed by a gradual diminution of its size. A year elapsed when the left foot fell under similar conditions of loss of sensibility and of size. Again, after a year-that is, two years after the numbness of the left hand, the right hand became similarly affected. Both hands are now contracted; their phalanges have been partly absorbed, and have much decreased in length; the joints of fingers are stiff, the original nails have fallen, and others distorted in shape and size have taken their place; muscles of the hands atrophied. No tubercles are to be found on any part of the body. Hair of head and other parts natural, excepting the shins and the backs of both hands, which are denuded of hair. The lower eyelid of right eye is drawn downwards and does not meet upper, leaving a portion of the globe of the eye exposed; lachrymation of this eye is constant, whilst that of the left is natural. Respiration free; general health good. His feet are partially atrophied, the toes flexed and diminished in size; they bear some resemblance to the forcibly contracted foot of a Chinese lady. This case is likewise mentioned by Dr. da Silva Beirao, in his Memoria acerca da Elephantiase dos Gregos, 1854.

CAse v. Lepra Tuberculosa.-A. G., aged 39, born in the island of Pico (Azores) in 1827; five years in San Lazaro. From the year 1843 to 1845 he worked as a jeweller in the city of Rio de Janeiro (Brazil). Left the city to hawk jewellery in the town of Campos, 150 miles inland. Father, mother, brother, and sister now living, and are free of the disease. Never had constitutional syphilis, though he had been the subject of gonorrhœa more than once before 1851. He suffered much from general itching of the body during this year; it was followed by a scaly eruption of the skin, tubercles then made their appearance on arms, chest thighs, and finally on face. The disease progressed in spite of all treatment; the tubercles on face have the appearance of huge folds of corrugated skin. which to the touch seem as if they contained fatty matter; he feels them sensible when thus touched by hand, but experiences no pain when pricked by pin. The epidermis of hands is furfuraceous, and the scales frequently peel off. No hair on head, eyebrows, eyelids, nor face, nor is there any on axillæ or pubes. Cornea nebulous, vision lost. The tubercles on nose are ulcerated and discharge. Respiration difficult, irregular, and at times much oppressed; nasal apertures contracted by tubercular deposit. The skin of forehead, of lips, and chin is furrowed by the deposition of leprous matter. Hands are large, skin on their back thick and in folds; in the palms it is scaly; the nails have a scabby appearance, and peel; sensibility of both hands almost entirely gone; sufficient remains to enable him to distinguish by touch the form of objects and the degree of their heat. He speaks of his general sensibility as being asleep. There are several tubercles on tongue, and likewise on the mucous membrane of the buccal cavity ; mastication is by them rendered diffcult. He is a married man; his wife and his two children are free of the disease which afflicts him. The colour of the tubercles is like that of the surrounding skin. He attributes the disease to a cold contracted by a checked perspiration. Ile has always lived well and generously, living on a flesh diet.

CaSe vi. September, 1866. Lepra Ancesthetica.-M. J. C., aged 52 , born near Alhandra, at Villa na Ruda, in 1814; has been two years in San Lazaro. Is a servant and general labourer. Has been married three times; his first marriage was celebrated thirty years ago. Both his father and mother died of yellow fever during the fatal epidemic of 1857. An elder brother of his, who died four years ago, was affected with the same form of leprosy under which he himself labours, and had lost all the fingers of his hands and the toes of his feet. The chief article of diet of both, when young, was fish; was never vaccinated; has had small-pox; never suffered from any form of syphilitic disease. After exposure to cold, sixteen years ago, when perspiration was checked, he experienced an itching of both legs, which, troublesome, was followed by small ulcers appearing on legs, of such a nature and extent as to incapacitate him from work. His hands shortly after became contracted, and their muscles underwent atrophy. The cartilage of the nose is now partly gone, the opening into nasal cavity contracted, rendering nasal respiration difficult. Respiration effected chiefly by mouth, which, from this circumstance, is as a rule dry. The alveolar processes of front part of upper maxilla are partially absorbed, and the incisors have fallen out; the upper lip unsupported falls. No hair on eyebrows nor on eyelids, whilst the hair of the head, beard, axillæ, and pubes is natural. At the commencement of the disease several tubercles appeared; there are none now.

CASE vir. September, 1866. Lepr $x$ Tuberculosa.-A. Z., aged 36 , born in Santa Iria, three leagues from Lisbon. Has been an inmate of San Lazaro for the last seven years. His occupation had been that of hawking fish; purchasing it in Lisbon, and selling it at Santa Iria. His diet consisted chiefly of fish. His mother and three married brothers and their children are all healthy; his father alone, now dead, was subject to the same form of tuberculous leprosy under which he is suffering. In a population of 700 , he and another are the only ones affected with leprosy, with this distinction, that whilst he has it in the tubercular form, the other has it in the anæsthetic. $\mathrm{He}$ is intelligent and observant. He remarked, some sixteen years ago, the appearance of several tubercular swellings on forearm and leg; and after the lapse of a year, others which affected the face and other parts of the body. Two years after the declaration of the first symptoms, the hair of eyebrows, eyelids, of forearms, and legs commenced to fall off, whilst that of other parts of body remained intact; the eyebrows are now entirely denuded of hair, whilst eyelashes are gradually disappearing. The skin is thickened, in patches, of a liver colour, and is insensible when pricked with a pin; the tubercles are flattened, not knobby. Both sight and hearing good, nose flattened, nasal apertures contracted; lobes of ears thickened. Tongue red, chapped, slightly ulcerated at tip ; part of soft palate ulcerated away; deglutition painful. Expectoration, mucous and abundant, sometimes streaked with blood. Respiration short, and at times hurried; he has a large throat cough. Breath tainted; lungs sound; never had syphilis. Hands contracted, their muscles atrophied, the skin covering them insensible when pricked; but where ulcerations obtain the application of lunar caustic occasions much pain. Nails displaced by the swelling of the fingers. Has several open ulcers on both feet; toes entire, sensibility less in hands than in toes. Though vaccinated, has had small-pox.

CASE virr. Lepra Anasthetica.-F. M , aged 64. Born in Casal Gudia, Malta. Has been thirty-four years in Portugal; his occupation has always been that of a iabourer in the fields. Sixteen years ago, after having suffered from general debility for seven 
previous years, he remarked that small tubercles made their appearance on the eyebrows; at the same time he experienced a loss of sensibility of the hands, together with a loss of power over their movements; he likewise felt they were stiff. Shortly after the fingers contracted and the muscles of the hands gradually atrophied; he has now lost the use of his hands. It was about two years ago that his vision commenced to fail him. At present all sight is gone; the eyeballs look like two masses of movable granulation; these masses are seemingly insensible, as he is unconscious of the many flies that settle upon them. Skin of face is smooth and, excepting eyebrows, is free of tuberculous growth or thickening; no hair on eyebrows nor eyelids. Both hands and feet are contracted, though no portion of them is lost. Respiration at times difficult. His diet has consisted chiefly of fish.

CASE IX. September, 1866. Lepra Ancesthetica.-E. M., aged 28. Born in Lameirao, seven leagues from Coimbra. Never vaccinated. Had small-pox when 8 years old; never had syphilis. Has been an inmate of San Lazaro for the last three years. Has lived chiefly on a fish diet, sometimes, but rarely, indulging in a meat diet. Lameirao, his native place, has a population of 150 ; for the last ten years there have been in it but two cases, a woman and himself. None of his family nor any member of its collateral branches had been the subject of leprosy. Ten years ago, when returning from his work in a state of perspiration, he drank cold water at a fountain by the roadside, was chilled, and was laid up with some affection of the chest, and so weakened was he by it that he never recovered the strength he had before. About six years ago he experienced numbness of the small finger of his left hand, which was soon followed by similar numbness of the other fingers of this same hand, and by a contracted state of these fingers ; numbness of the fingers of the right hand was now felt ; contraction followed, and both hands became useless. His intellect is bright and his perception quick. Left eye is inflamed, its vision dim. Hair on eyebrows and eyelids is fast disappearing ; skin of eyebrows and cheeks furfuraceous, and, where so, colour is of a dusky hue. Cartilage of nose depressed, nasal orifices contracted. Respiration laboured. Prefers cold to warm weather. Legs are swollen, but do not pit on pressure. Skin of legs of a dark hue, scaly in parts; several cicatrices of old ulcers are met with on them. Never had any tubercles on any part of the body. $\mathrm{He}$ labours under a sense of great lassitude, which disables him from all manual work.

CASE x. September, 1866. Lepra Ancesthetica.-A. L., aged 52. Born in Adanay, near Alhandra; five years in San Lazaro, a labourer. Several of the members of his mother's family have suffered from both forms of leprosy (morphœa and gafeira); none of his father's family. Never vaccinated. Had small-pox at the age of 14. Has had scabies, measles, scarlatina, and ague, but no syphilis. He was freely bled when suffering from scarlatina. He attributes his present state to the loss of blood he then sustained, for it was very shortly after this loss that numbness of the hands appeared. The phalanges of both hands have been absorbed; the truncated palms alone remain. He states that he frequently wounded his fingers with tools he was in the habit of using without being conscious of what he had done; the wounds enlarged, fingers then contracted, and finally disappeared. Vision of right eye weak ; deaf of left ear; hair of head, of eyebrows, and eyelids natural ; sensibility of hands, of forearms, of legs, and feet almost nil. Several of the toes are absent. Skin over body fur.. furaceous. Never had any tubercle. Is intelligent, perspires much, and is very weak; he nevertheless attempts and does some little work.

CASE XI. January, 1867. Lepra Ancesthetica.-J. J. F., aged 30, housemaid. Born in Alcavadre, in Conceiho de Leiria, four leagues from Thomar. She has lived nine years in Lisbon, five of them in San Lazaro. Her father and her brother were affected with morphœa, whilst she and her sister (Case xII) suffered from gafeira. She was 14 years old when her father commenced to show symptoms of disease in himself; so that if we admit her leprosy to have been due to hereditary transmission, the germ communicated must have had existence in the father's system at the time of conception, and, consequently, must have lain dormant for fourteen years at least in himself, as the ieprous symptoms in him only manifested themselves after that lapse of time. In her the disease first appeared when in her 24th year; the hands became numbed, stiff, contracted, and partly shrunk; though thus mutilated by the disease, she is able to thread a needle and sew. Her diet, when at home, consisted chiefly of fish, and that bacalhao or sardines.
Case XII. January, 1867. Lepra Ancesthetica.-F. F., aged 24, housemaid; sister of the above. When 18 years of age she remarked her legs to swell, the skin of them scaly, and ulcers to break out. Hands have lost much of their sensibility; hair of eyebrows and eyelids gone. Diet chiefly fish, like that of her sister's. She was bled freely when symptoms first made their appearance; to this loss of blood she considers the disease attributable. The mother of these sisters never suffered from any skin disease.

CASE XIII. April, 1867. Lepra Ancesthetica.-J. D., aged 30, labourer. Born in Alcoentre. Admitted into San Lazaro February, 1867. Father died twelve years ago, at the age of 70 ; mother, aged 60 , is alive; neither suffered from any leprous complaint. He is the first and the only one of his family affected with the disease. Diet chiefly fish; seldom has tasted flesh meat. Has had small-pox, measles, and scabies. When 12 years old he suffered from a severe cold, from whence, whilst recovering, he observed stiffness in both hands, which shortly afterwards became contracted. Eyebrows and eyelids denuded of hair. Sight of both eyes lost; on each cornea a tubercle protrudes; both eyes inflamed, the right suppurating. Hands and feet contracted, their muscles atrophied. In both hands the anæsthesia obtains to one inch above wrists; forearms and arms are sensible to touch. Respiration sometimes short; hearing good.

Case XIV. April, 1867. Lepra Tuberculosa.-B. V., aged 24, servant. Born at Orense, in Galicia. No member of his family has ever been affected with either morphœa or gafeira. Came to Lisbon in 1840, and was employed as servant, water-carrier, and cook. In 1850 contracted syphilis, and, whilst under treatment, caught cold; to this affection he attributes his present disease. In 1852 he married, but never had cliildren. In 1854 he went to Brazil. About this time he remarked that the hair of eyebrows and eyelids was gradually disappearing; tubercles then made their appearance on eyebrows and cheeks; as they enlarged, they became of a dusky hue. The hands, cdematous, are useless for any practical purpose ; skin dark, fingers ulcerated; voice hoarse, deglutition painful; soft palate thickened and ulcerated. Believes that were he supplied with more food he might be cured, for he remarks that, with insufficiency of food, the malady makes more rapid progress. $\mathrm{He}$ is anxious to use an external embrocation made by heating a quart of olive-oil in which a toad recently taken is immersed, and reducing it to the quantity of a pint, when it is fit for use. He spoke of one who had been cured by it, whose address he gave me, and whom I visited, but could not, after examination, confirm his glowing statements as to the beneficial effects of this application.

CASE Xv. April, 1867. Lepra Tuberculosa.-A. F., aged 40, agricultural labourer, unmarried; born in the environs of Coimbra, five leagues from the Atlantic. None of his family are affected with the disease; never knew of anyone in his own village having the disease; remembers only to have seen it in a district some distance from his village. Diet has chiefly consisted of bacalhao, sardines, and vegetables. Has been twenty-four years in Lisbon working as labourer. Has suffered from the disease for the last seven years. Cannot assign any cause for its appearance. His face, ears, nape of neck, and upper part of throat are covered with tubercular masses; these tubercles are large, prominent, and pedunculated; they are unlike the tubercles generally observed, which lie upon the skin in little mounds, their base being broadest. Ears large, conchæ contracted, almost closed by the pachydermatous thickening of the tissues; the helices and lobes are mon. strous; some of the tubercles on the nape of the neck resemble a flattened bunch of grapes-as if in basso-relievo. Throat painful, voice hoarse, coughs when speaking. Breath much tainted; eyesight weak, tubercles from eyelids hang, obstructing what sight ne has. Is subject to headaches. Face covered with tubercles; eyebrows, eyelids, and lower lip thickened by them. Skin of abdomen thickened and in folds-all these masses are of a dark, dusky colour. Soft palate ulcerated. Eyebrows and eyelids bereft of hair.

CASE XVI. April, 1867. Lepra Tuberculosa.-A. G. P., aged 47, servant, born in San Guillon de Freixa, in the Minho. Has been thirteen years in Lisbon. Has had constitutional syphilis. None of his family have ever been affected with leprosy. His diet has consisted of fish and vegetables, seldom touching flesh meat. Suffered from ague for five months when 28 years of age; never afterwards regained his former strength; he then became subject to flushings of the head and face, which for one year distressed him greatly; tubercles then appeared on eyebrows and 
other parts of body, increasing by time in size and number. Face is now studded with tubercles; the skin is puckered in folds, which gives a bloated appearance to the features; when these folds and tubercles are handled they feel like masses of adipose substance. Ears are not affected. Conjunctivæ of both eyes congested and thickened; eyesight weak. Though the soft palate is ulcerated, voice is clear, and talking does not distress him. Anæsthesia of skin of hands and part of forearms and of lower limbs as high as knees. No hair on eyebrows or eyelids.

CAUSES.-Several have been the factors assigned as causes in the generation of this disease; among them a special and exclusive diet, heredity, contagion, and endemicity have held the first place. The majority of the subjects whose cases are related above had lived on the seaboard of Portugal, or at no great distance from it, using fish as their chief diet, seldom indulging in the use of flesh meat. To this exclusive article of diet the majority attributed the disease, and many a thinking mind, both lay and medical, strengthened by the evidence which came before them, inclined towards believing that in fish -and in salt fish especially-there lurked some element which, under certain predisposing conditions, effected an inroad into the system, and elicited the symptoms such as are witnessed in leprosy. They observed that in those districts where flesh meat was readily and cheaply obtained, there the disease had little hold. In Alemtejo, for example, where pork is in general use, neither morphœa nor gafeira is known.

A very large quantity of salt cod-fish (bacalhao) is yearly imported from Newfoundlamd, which, from its cheapness and quantity is used largely by the people of Portugal. Besides this, salt cod, sardines, salted tunny, and other salted fish are used likewise. All classes-rich and poor-among the Portuguese eat fish on Fridays and Saturdays throughout the year.

The question of heredity is adopted by some, denied by many for so strange and eccentric are the modes and manner of transmission that hesitation takes its stand at the threshold, and fails to accept it as the "vera causa" of the disease.

The experience which has afforded so many and such startling instances in what has been witnessed in the island of Molokai (Sandwich group) goes much towards establishing a belief in contagion by microbian transmission. If we admit the existence of a microbe as cause and not effect of the disease, we may find a raison d'être for the manifestations observed in the discovery of the "bacillus lepræ " made Dr. Armauer Hansen.

Endemicity is only found in localities where leprosy is already in existence, as in villages in the colonies set aside for the reception of lepers. When therefore communicated it is due not to any endemic peculiarity attached to the soil, but to the presence of a leprous person, and therefore takes rank with contagion.

of the above sixteen cases, nine presented symptoms which characterise the anæsthetic type, whilst seven offered those of the tubercular. These two types are unlike; the symptoms they present differ materially one from the other. For in one (lepra anæsthetica) we observe a greater loss of æsthesia; a contraction and loss of fingers and toes, and an atrophy of the muscles of both hands and feet. The nasal cavity, the openings of the pharynx and larynx are contracted and in such guise as to implicate respiration, and thus threaten life. Whilst the anæsthetic is thus characterised, the lepra tuberculosa on its part is marked by a generation of successive tubercular growths over part or whole of body; by a corrugated and thickened state of the skin, by a loss of the hair of the head and of other parts of body. Both are termed leprosy, but symptoms obtain in one which differentiate it from the other. These marked differences are met with in individuals composing one and the same family; for while one member is affected with the symptoms of the anæsthetic form, another evinces those of the tubercular.

On investigating and probing the different circumstances which influence the protean forms that occur in one and the same family, we are at a loss to account for the difference. Both are the issue of the same parents, both have lived under the same hygienic conditions, and on an exclusively fish diet, both have been subjected to factors of similar nature and powers, yet, when affected, each expresses the disease in his person differently.

It naturally occurs to the mind that where two diseases obtain, with characteristics individualising each, there must be at work separate and distinct factors to create the differences which offer in each. We have observed a body of men encamped in malarious districts, subjected to similar conditions of exposure, of food, of position, and of work, falling victims at the same time to distinct and separate affections, as dysentery and remittent fever, and we could not but bring ourselves to believe that two distinct causes were in operation at the same time; one attacking the liver and intestinal canal causing dysentery, the other using its full force upon the corpuscles of the blood and making rude advances upon the parenchyma of the spleen, declaring itself remittent fever both in action at the same time, both however inducing different results.

In so speculative a science as that of medicine, dogmatic assertions can find no place, for when ventured upon, scepticism steps in, leavens the mass, and shrouds with doubt every postulate assumed. Nevertheless, bacteridian histology has of late years made such gigantic strides, and with steps so firm, that there now obtains a tendency towards accepting its conclusions as a reason for the existence of the many specific diseases which fall under observation, and of giving importance to the existence and presence of microbes as the fons et origo of these specific diseases. Yet in so pronouncing and accepting this theory, we cannot help indulging the hope that-when histolozical research is pushed to a final and logical conclusion-the causes in operation which result in the dissimilar and different manifestations we now witness in the anæsthetic and tubercular forms of leprosy may be found to be different in nature, as different and as marked as those which distinguish typhus from typhoid fever.

There is some reason to believe that the anæsthesia which distinguishes these two forms of leprosy is due to the choice of place of the deposited lymphoid matter; in the anæsthetic the interstices between the nerve fibre in the site pressing, by its presence, upon the nerve, and impairing its function; in the tubercular it elects the swellings themselves.

Some have believed to have found a resemblance with scurvy in the plastic deposit, the fœetid breath and livid colour of the skin, for in both scurvy and leprosy these symptoms obtain, but this seeming analogy is set at rest when the history, the cause, and the progress of each disease are studied and observed.

Treatment. - In the treatment of this disease the hygienic, the dietetic, and the palliative had more influence than the therapeutic. Where the cleansing of the skin by baths could be effected; where soothing or stimulating applications were made to ulcerated surfaces and to skin, to allay the distressing symptom of prurigo; where good and abundant food was given, fresh air obtained, and exercise without fatigue taken, with attention to full ventilation of inhabited rooms, where measures were adopted to afford recreation and gentle excitement, and thus divert the mind from the disease itself, a marked difference and a decided improvement were the consequence. Under these influences the disease made little advance. But it is one that follows a determined course, rapid in some, more dilatory and seemingly stationary in others, but never retrogressing, always advancing.

Where drugs were administered internally, I remarked that only those possessed of dietetic properties-as for example, cod-liver oil-were of any value. Mercury, arsenic, iodide of potassium, assacú (obtained by incisions into the bark of the hura brasiliensis), ammonia, and other preparations, each acted on the system, modo suo, but not in the measure or way hoped for.

It was observed that man and wife, having no apparent disease upon them at the time of conception, having begotten a healthy family, have, nevertheless, towards the decline of life, fallen victims themselves to the disease, their children never manifesting any symptom at any time of their life. Married couples, free of leprous disease, have given birth to children who afterwards became lepers. Parents, perfectly free of all leprous taint throughout, have given birth to children in whom, at a later period of their lives, leprosy has declared itself. Instances of the disease have occurred in one family where it assumed different forms, one taking the form of morphœa, another that of gafeira. The disease has declared itself in a member of a family perfectly free, together with its collateral branches, of all leprous affections.

Though in former days Egypt was accredited with having originated the disease, as Lucretius in the sixth book of his De Rerum Naturâ says:

Est elephas morbus qui propter flumina Nili

Gignitur Ægypto in mediâ neque preterea usquam. ${ }^{1}$

we find it in existence over the world, and, unfortunately, in great numbers in the lands which acknowledge British rule; in the West Indies, in Mauritius, and Seychelles the disease is found. In 1866 in India, with a population of $210,767,504$ there were 124,924 affected with leprosy. 
The causes of the origin, the progress and the mode of propagation being in great measure known to us, we possess a remedy at hand, which, if carried to its legitimate ends, will result in immense good. I do not mean by this that a law similar to the ancient law of Epirus should be called in requisition to restrict or suppress it; but, by a system of precaution, of segregation, and by regulations influenced and dictated by a spirit of Christian charity - a duty imperative upon England-a certainty may be arrived at, and a means found by which this loathsome disease, if not wholly stamped out, will meet with so effective a check, and be so controlled, as to soften down the ravages it now makes, and curb the facility of its propagation.

\section{SUMMARY OF THREE LECTURES}

or

\section{TRANSFUSION : \\ ITS}

\section{PHYSIOL()GY, PATHOLOGY, AND PRACTICE. Delivered at the Royal College of Surgeons.}

By WILLIAM HUNTER, M.D., M.R.C.P., M.R.C.S., F.R.S.E., John Lucas Walker Student in Pathology, Cambridge; Arris and Gale Lecturer, Royal College of Surgeons.

LECTURE III.

THE respiratory as well as the hæmogenic value of transfused blood is subject to the same conditions, and depends on the same two factors-(1) the quantity of blood transfused, (2) the nature of the blood destruction in progress at the time of the transfusion.

The greater the quantity of blood transfused, the longer are red corpuscles likely to remain within the circulation, and the more likely is their hæmoglobin and the iron it contains to remain within the system. Over this factor, however, we can exercise but little control. The quantity of blood transfusible in man can rarely be more than about 5 per cent. of the quantity of blood already in the body. And the life-duration of the red corpuscles under such circumstances is probably to be reckoned by a period of hours.

Of far more importance as a factor is the nature of the blood destruction at the time of the transfusion and subsequent to it. The more the blood destruction is " active," the shorter is the lifeduration of the red corpuscles; and how active this may at times be is evidenced by cases in which the transfusion is followed almost immediately by rigors, fever, and the appearance of free hæmoglobin in the urine. There are certain forms of anæmia in which excessive blood destruction is the essential feature, and these from their very nature are certainly unsuitable for transfusion. We shall presently see that it is possible for us to recognise by certain clinical features the nature of the anæmia we have to deal with, and in this way to avoid the operation of transfusion under circumstances that would probably render it of little, if any, service. In addition to these pathological variations, the activity of blood destruction is, as we have seen, subject to certain physiological variations chiefly having relation to the ingestion of food ; and this factor it is in our power to some extent to control by having regard both to the quantity and quality of food subsequent to the transfusion. Our object would be best attained by withholding food altogether, in this way rendering blood destruction, as far as possible, "passive." In any case the food should be as little nitrogenous as possible, since a nitrogenous diet undoubtedly increases blood destruction more than a simple carbohydrate one.

Physiological Action of Sodidm Phosphate.

It is by interfering with this-what may be regarded as the primary-indication in transfusion, namely, to reduce blood destruction to a minimum, that the use of sodium phosphate for purposes of transfusion to prevent coagulation of the blood is attended with certain disadvantages that require here to be noted. First recommended now some years since by Dr. Braxton Hicks and Dr. Barnes, the use of this salt has recently been revived, apparently with much success, in the hands of Mr. Cotterill, Dr. John Duncan, and others.

This practice of mixing the blood with saline solutions before injection, and in this way getting rid of certain of the dangers incidental to the operation, is based on an assumption that is as erroneous as it is widespread, namely, that the behaviour of salts, poisons, etc., on the red corpuscles outside the body affords any clue to their probable behaviour on the blood after their injection. The conditions of an experiment outside the body and those existing within the body are entirely different. Outside, the condition $\mathrm{s}$ are physical; we mix the blood with the solution whose action is being studied, and allow the red corpuscles to remain at rest, and in contact more or less prolonged with the substance whose action is being studied under conditions that are entirely without parallel within the body. Within the body the conditions are physiological: the blood is constantly in rapid circulation; all the processes, including the process of blood destruction, are the result of the activity of cells, and may be modified in many ways by the action of the drug introduced.

The facility with which blood can be withdrawn from the body, and the action of drugs on its corpuscles studied, has led to many erroneous conclusions regarding the behaviour of various drugs on the blood. The following observations may serve to emphasise the above conclusions :-I have found a $\frac{3}{4}$ per cent. solution of sodinm chloride to cause red corpuscles to break up and disappear in the course of twenty-four hours, while the same solution, after the addition of toluylendiamine in the proportion of $\frac{1}{2}$ per cent. to 1 per cent., preserved them intact for several days. The two observations were made at the same time, and the conditions were precisely the same in both.

Nevertheless, the injection of the simple saline solution into the circulation, even in the largest quantities, is harmless, while the injection of a few cubic centimètres of a 1 per cent. solution of toluylendiamine causes a most marked destruction of the red corpuscles, accompanied, it may be, by jaundice, hæmoglobinuria, or even death.

The bearing which these observations have on the value of the practice of injecting sodium phosphate with the blood transfused will be evident. Its behaviour towards the corpuscles outside the body affords no criterion of its probable behaviour after injection. In all cases bodies so introduced are in the position of foreign bodies. Their action will be harmless only on one conditionnamely, that they affect in no way the activity of the cells of the blood on the one hand, or of the blood organs on the other. My observations show that in the case of sodium phosphate this condition is not fulfilled.

In every instance in which the salt was injected along with the blood, the subsequent blood destruction was of a more active character than that observed after transfusion of pure defibrinated blood alone, although the conditions of the experiments were precisely the same in all cases. (Fig. 14.) The evidence of this more active destruction was, in addition to the shorter life duration of the corpuscles as determined by enumeration (Fig. 14), of a twofold nature: 1 . The presence of iron in the liver in larger amount than was ever observed in any experiment in which blood alone was transfused, the pigment in which this iron was contained being found in the situation most characteristic of excessive blood destruction-namely, within the liver cells; and (2) an increase in the colouring matters of the fæces pointing to an increased formation of bile pigments.

Clinical evidence of a similar change in the character and amount of the bile excreted after transfusion is, I beieve, afforded by an interesting case recorded by Dr. Halliday Croom. ${ }^{1}$ On the day following transfusion of a mixture containing $5 \frac{1}{2}$ ounces of blood and $2 \frac{1}{2}$ ounces of a 5 per cent. solution of sodium phosphate, there was a well-marked attack of jaundice. It is possible that the occurrence of the jaundice subsequent to the transfusion may have been a mere coincidence, but recent observations tend more and more to establish the importance and frequency of that form of jaundice depending on increased destruction of blood, sometimes termed "hæmohepatogenous," but whose essential feature, I believe, may be best described by terming it "hæmolytic." By far the best example of this form of jaundice is that so frequently met with in pernicious anæmia. The sudden onset of the jaundice in the above case after the transfusion, as well as its brief duration (it began to fade at once, and had disappeared at the end of a week), points in all probability to a causal connection of this kind between it and the injection.

The use of salts for purposes of transfusion is, to a great extent, based on the assumption that the composition of the plasma, as regards its richness in inorganic solids, is constantly varying, and that the injection of a little more or less is immaterial. So far 